\title{
A Study on Conversational Strategies of Chinese Country Doctors with Their Patients from the Perspective of Social Psychological Pragmatics
}

\author{
Zhongtang Wei \\ School of Foreign Languages, Qilu Normal University, Jinan, China \\ Email address: \\ 122533893@qq.com \\ To cite this article: \\ Zhongtang Wei. A Study on Conversational Strategies of Chinese Country Doctors with Their Patients from the Perspective of Social \\ Psychological Pragmatics. International Journal of Language and Linguistics. Vol. 9, No. 5, 2021, pp. 233-246. \\ doi: $10.11648 /$ j.ij11.20210905.11
}

Received: August 17, 2021; Accepted: September 9, 2021; Published: September 23, 2021

\begin{abstract}
Conversational strategies are the techniques that help speakers to maintain conversations going smoothly and to achieve the communicative goals. Via adopting the method of fieldwork and empirical research to collect authentic country doctor-patient conversations and making qualitative analysis with basic quantitative analysis as supplement, this study probed into the conversational strategies implemented by Chinese country doctors in communicating with their patients and furthermore, explored the social psychological functions and effects of each conversational strategy. Via collecting and analyzing 217 conversations between 10 Chinese country doctors aged from 35 to 45 with 217 patients, the author found that 12 conversational strategies were employed by Chinese country doctors to help their patients be more cooperative in the process of diagnosis and more positive and active to the treatment, which were greeting, enquiry, instruction in diagnosis, data display, assertion, instruction after diagnosis, explanation, comparison, comforting, praise, warning, and kinship address. Moreover, instruction in diagnosis consists of two kinds which are direct instruction and instruction with request. Instruction after diagnosis consists of three types which are simple instruction, instruction with negation, and instruction with consultation. Explanation consists of four different ways which are explanation with medical knowledge, explanation with government policy, explanation with patient's behavior, and explanation with slang. Comparison consists of two parts which are vertical comparison and horizontal comparison, and horizontal comparison is further divided into two kinds which are upward comparison and downward comparison. Additionally, different conversational strategies observed or violated different maxims of politeness principle and thus, caused different topical and social psychological functions and effects on patients and thus, help them be more cooperative and positive.
\end{abstract}

Keywords: Conversational Strategy, Doctor-Patient Conversation, Chinese Country Doctor, Social Psychological Pragmatics

\section{Introduction}

Researchers have offered different definitions and explanations of conversational strategies from distinct angles. Dörnyei and Thurrell [8] defined conversational strategies as "an invaluable means of dealing with communication 'trouble spots', such as not knowing a particular word, or misunderstanding the other speaker". They thought that conversational strategies "can also enhance fluency and add to the efficiency of communication" [8]. Riggenbach [25] regarded conversational strategies as certain conscious ways to help maintain communication. Kehe and Kehe [14] proposed that conversational strategies are techniques that help speakers and listens sustain the conversation going smoothly to obtain conversation goals. Nguyet and Mai [20] defined conversational strategies as "strategies which help speakers to maintain a conversation and to achieve their communicative goal". This study is designed to describe conversational strategies as techniques that help country doctors sustain the conversations with their patients going smoothly and make their patients be more cooperative in the process of diagnosis and be more positive and active in treatment. Conversational strategies are important verbal techniques which can help people make better utterances and obtain different conversational or interpersonal goals. Consequently, conversational strategies have aroused many linguistic researchers' interests to carry out 
studies from various perspectives in different fields $[5,7,15,17$, $22,23,26]$.

In the current operation of medical system, country doctors who live and work in villages are responsible for the treatment of their patients who are villagers in most cases, and should also go to villagers' houses, especially those who are over sixty-five years old or who suffer from hypertension, diabetes, or severe mental disorder, to enquire their health status and rehabilitation once a season, and then record all of the information and send it to the township hospital. In this way, doctors in township hospitals can know the health conditions of those patients and those villagers over sixty-five years old in time, and give them more suggestions or instructions when it is necessary, which is better for patients' treatment and recovery and better for senior citizens to keep in good health in turn. Therefore, country doctor is an important bridge connecting villagers and medical systems of higher level. The conversations between doctors and patients are closely related to nearly every one of us. Therefore, the study on doctor-patient conversations is of exceptionally great significance. In consequence, many researches have been carried out from different perspectives and fruitful results have been achieved [4, 9, 21, 24, 34-36].

However, few researches have focused on the conversational strategies of Chinese country doctors or have directed attention on the conversations between Chinese country doctors and their patients. Therefore, this study aims at, first, finding out the conversational strategies adopted by Chinese country doctors in communicating with their patients so as to provide some new inspirations to health professionals to better communicate with and help their patients, and second, exploring the social psychological functions and effects of the conversational strategies so as to delineate the social psychology of Chinese country doctors and patients deeper and clearer.

\section{Social Psychological Pragmatics}

The term social psychological pragmatics was first put forward by Turnbull and Saxton in 1997 in their article "Modal expressions as facework in refusals to comply with requests: I think I should say 'no' right now" and is defined as "the psychological analysis of how linguistic resources are used to do interpersonal work" [29]. In 1998, in the article "Conversational structure and facework in arguing", Muntigl and Turnbull claimed that social psychological pragmatics is a "new and developing approach to analyzing interaction" [18]. They reckoned that the central assumption sof social psychological pragmatics is that "conversation both creates and reveals social structure" [18], and its overriding concern is "to provide an analysis of the mutual influence of conversation and social structure" [18]. Holtgraves [12] made more systematic investigations into the relations between language use and social psychology in his book "Language as social action: social psychology and language use". He thought that language use is not only an action, but also a social action, an interpersonal action, a contextualized action, a coordinated action, and a thoughtful action, an action involving other people. He further illustrated that "it is a social psychological perspective in the sense that language will be viewed as a behavior that is both influenced by other people, as well as a means for influencing the behavior of others." [12].

Chen [2] discussed the research topics of social psychological pragmatics in his article "Pragmatic studies: the social psychological perspective". He claimed that social psychological pragmatics focuses on the social basis of language use, the interpersonal resources in language, and the interpersonal consequences of communication. In a narrow sense, social psychological pragmatics focuses on the individual psychology or interpersonal relationship involved in the communication between individuals, which can be concluded as how people use language resources to do interpersonal work, including how to persuade, how to construct and present self-image and others' image, how to express or eliminate prejudice, how to promote interpersonal relationship, how to establish equal or affinity relationship, etc In a broad sense, social psychological pragmatics focuses on the psychologies of individuals, groups, or societies involved in communication in the public domain, such as advertisements, logos, promotions, news, etc. Chen [2] demonstrated an example of analyzing the influence of interpersonal relationship on expressing and understanding utterance through the lens of social psychological pragmatics:

Wife: What time did you get home last night?

Husband: After 12 a.m. I played cards with friends for a while.

In daily communication, what people say and how they say it are not only influenced by the communicative purpose itself, but also by the interpersonal relationship. Once we take interpersonal factors into account, we can easily make a correct interpretation of the utterance and reveal its "social-psychological effects" [1]. In the dialogues above, considering the social relationship between two sides, we can get that the husband's additional words "I played cards with friends for a while" are said for a reason. Even though it has nothing to do with his wife's question, but its importance is social psychological rather than topical. It plays a crucial role in eliminating misunderstandings and maintaining a harmonious relationship for him with his wife, for the implication of that sentence is that he did not do anything else with anyone else last night.

According to Holtgraves [12], politeness principle, face theory, and speech accommodation theory are all closely related to social psychology in language use, so they can all be treated as the theories in the domain of social psychological pragmatics and implemented as the theoretical framework for academic studies from the perspective of social psychological pragmatics. In the present research, politeness principle is chosen as the theoretical framework for interpreting the social psychological effects and functions of the conversational strategies employed by Chinese country doctors with their patients, for politeness is of extreme importance for doctors in the interactions with their patients.

Politeness principle proposed by Leech [16] plays an important role in the field of pragmatics researches. It is not 
regarded as another principle to be added to the cooperative principle, but it saves cooperate principle, for politeness principle explains the reasons people intentionally violate the cooperative principle. Leech [16] elaborates politeness principle into six maxims, each of which has two sub-maxims that are essentially considered asymmetrical as follows:

1. Tact Maxim: the speaker minimizes the cost to the listener or others and correspondingly maximizes the benefit to the other side.

a. Minimize cost to others

[b. Maximize benefit to other]

2. Generosity Maxim: the speaker minimizes benefit to himself/herself but maximizes cost to himself/herself.

a. Minimize benefit to self

[b. Maximize cost to self]

3. Approbation Maxim: the speaker minimizes dispraise of others but maximizes praise of others.

a. Minimizes dispraise of other

[b. Maximize praise of other]

4. Modesty Maxim: the speaker minimizes praise of himself/herself and maximizes dispraise of himself/herself.

a. Minimize praise of self

[b. Maximize dispraise of self]

5. Agreement Maxim: the speaker minimizes disagreement between himself/herself and others, but he or she maximizes agreement between self and others.

a. Minimize disagreement between self and others

[b. Maximize agreement between self and other]

6. Sympathy Maxim: the speaker minimizes antipathy between himself/herself and others, but maximizes sympathy between him/herself and others.

a. Minimize antipathy between self and other

[b. Maximize sympathy between self and other]

As the six maxims states, Leech's politeness principle deals the relationship between two participants, self and other. Besides, it is obvious that tact maxim and generosity maxim, approbation maxim and modesty maxim, are two aspects of the same issue respectively. It is also obvious that within each maxim, the sub-maxim $b$ appears to be less important than the sub-maxim a, which reflects a more general law that negative politeness or avoidance of discord is a more weighty consideration than positive politeness or seeking concord. In addition, speakers may adhere to more than one maxim of politeness at the same time. One maxim is often on the forefront of the utterance with a second maxim being invoked by implication.

Politeness principle is of irreplaceable significance in communication, which can help interlocutors maintain the social equilibrium so as to keep amicable, cooperative, and harmonious relationships.

\section{Methodology}

\subsection{Method}

First, the present study collects and analyzes the authentic country doctor-patient conversations and thus adopts the method of fieldwork and empirical research. Second, the present study is principally based on the qualitative analysis of the data, with basic quantitative analysis as supplement. Quantitative analysis mainly focuses on the statistics of the distribution of different conversational strategies by Chinese country doctors with their patients, and qualitative analysis is made to provide a detailed and in-depth exploration of the social psychological functions and effects of each conversational strategy, aiming at examining how these strategies are employed to help patients be more cooperative with the diagnosis and more active to the treatment.

\subsection{Subjects and Data Collection}

Table 1. Subjects and data collection.

\begin{tabular}{llllll}
\hline Subjects & Age of Subjects & Number of Patients & Number of Conversations & Total Time of Conversations & Time of Collection \\
\hline $\begin{array}{l}10 \text { male } \\
\text { country }\end{array}$ & From 35 to 45 & & 6 hours \\
doctors & & 217 & 217 & 58 minutes \\
\hline
\end{tabular}

In order to facilitate the abundance of the date and improve the objectivity and validity of the study, this study does not focus on just one country doctor nor conversations between country doctors with a few of patients. As it is shown in Table 1 , the subjects of the present research are 10 male country doctors aged from 35 to 45 from one province in China. Those ten doctors are chosen as the subjects for two reasons mainly. First, they all have been doctors for more than five years, so they have captured some verbal techniques to better communicate with their patients. Second, the villages where they live all have large populations, so it is convenient for collecting data.

From March to April in 2019, the author recorded 217 complete conversations in total between the ten country doctors with 217 patients from 15 villages of the same province with an intelligent phone. Before recording, the country doctors and their patients were all informed and agreed. During recording the conversations, the author was not at the scene, in order to let the country doctors and patients talk naturally and thus to exert any negative influence on the data collection. The total recording time is 6 hours and 58 minutes and 30 seconds.

\subsection{Research Procedure}

The present research is conducted in five procedures, which are recording the data, listening to the data repeatedly, transcribing the data in detail, analyzing the result, and 
reporting the result. After collecting the data, the author listened to it repeatedly, and transcribed every Chinese character in the data. All together there were more than 38,000 Chinese characters. During the process of transcription, on the purpose of the protection of confidentiality and privacy, all of the names of places were anonymous and all of the names of country doctors and patients were replaced with pseudonyms and not differentiated. Moreover, considering the readers of this thesis may have English speakers, the data was also translated into English in the second line.

The author analyzed the transcriptions with carefulness and sorted out all of the conversational strategies adopted by country doctors with their patients, and then made systematic classification of the strategies and also did statistics, and further described in detail and discussed in depth each conversational strategy and the conversations in which the strategies are employed. The choice of the conversations for interpreting each conversational strategy is based on the following principles. First, if the conversational strategy is implemented in multiple doctor-patient conversations, the ones that are representative are chosen. Second, if the conversational strategy is utilized only in one doctor-patient conversation, that one is chosen.

After depicting and interpreting the conversational strategies, based on the frequency and context of the implementation of each conversational strategy, the author discussed when the strategies are needed in actual doctor-patient conversations.

\section{Conversational Strategies of Chinese Country Doctors}

Through the observation, comparison, and analysis of the corpus, it is found that in the communications with their patients, country doctors utilize 12 distinct conversational strategies to better communicate with them and help them recover, which are greeting, enquiry, instruction in diagnosis, data display, assertion, instruction after diagnosis, explanation, comparison, comforting, praise, warning, and kinship address. The number and distribution of each conversational strategy are sketched in Table 2.

Table 2. Conversational Strategies of Chinese Country Doctors with Patients.

\begin{tabular}{lll}
\hline Name & Number & Proportion \\
\hline Greeting & 26 & $11.98 \%$ \\
Enquiry & 217 & $100 \%$ \\
Instruction in Diagnosis & 80 & $36.87 \%$ \\
Data Display & 151 & $69.59 \%$ \\
Assertion & 217 & $100 \%$ \\
Instruction after Diagnosis & 217 & $100 \%$ \\
Explanation & 66 & $30.41 \%$ \\
Comparison & 10 & $4.61 \%$ \\
Comforting & 28 & $12.90 \%$ \\
Praise & 39 & $17.97 \%$ \\
Warning & 11 & $5.07 \%$ \\
Kinship Address & 59 & $27.19 \%$ \\
\hline
\end{tabular}

As it is demonstrated in the table above, the conversational strategies which are used the most commonly are enquiry, assertion, and instruction after diagnosis (all 217, 100\%). In 217 complete country doctor-patient conversations, these are implemented is every dialogue, which shows that enquiry, assertion, and instruction after diagnosis are the most essential components of doctor-patient conversations and the most common conversational strategies by country doctors. The following one is data display $(151,69.59 \%)$. In much more than half of the corpus, country doctors show to their patients the data of their blood pressure and blood sugar, which is related closely to the type of country doctors' medical work.

In more than one third of the conversations, instruction in diagnosis $(80,36.87 \%)$ and explanation $(66,30.41 \%)$ are employed, which is followed by kinship address $(59,27.19 \%)$ that is more than one fourth. Praise $(39,17.97 \%)$, comforting $(28,12.90 \%)$, greeting is relatively less used, which is less than one fifth. Warning is implemented in only 11 conversations, which is about five percent of the total. Comparison is the least utilized conversational strategy by country doctors $(10,4.61 \%)$, which is less than five percent of 217 dialogues.

The use and function of each conversational strategy is delineated in detail and interpreted in depth through the lens of politeness principle in the following.

\subsection{Greeting}

The definition of greeting is that "something friendly that you say or do when you meet someone" [27]. The following are two examples. $(\mathrm{D}=$ doctor, $\mathrm{P}=$ patient $)$.

(1) D: How do you do?

P: How do you do?

(2) D: Hello!

$\mathrm{P}: \mathrm{Hi}$.

As the two examples show, at the very beginning of the doctor-patient dialogues, country doctors greet their patients who come into the clinics before asking about their health condition. While greeting has nothing to do with diagnosis, its importance is not semantic but pragmatic, not topical but social psychological. It is common that people would feel nervous when go to the hospital or clinics, but the greeting from the health professionals can reduce their nervousness. Therefore, when country doctors greet their patients who just come into the clinics, they observe the tact maxim by minimizing the psychological cost of their patients, which not only shows the politeness of country doctors, but also helps to make patients feel warm and less nervous, and correspondingly, will help patients to be more cooperative in the later diagnosis, and furthermore, will be better for both patients and doctors.

\subsection{Enquiry}

The definition of enquiry is that "the act of asking questions or collecting information about somebody or something" [13]. Enquiry plays a crucial role in the process of diagnosis, because it is an approach of indispensable importance for doctors to know their patients' health conditions and to further 
examine their physical problems. The occurrence, development, change process, and treatment process of the disease, as well as patient's self-conscious symptoms, living habits, eating habits, and so on, are the important basis for diagnosing the disease, and can only be obtained by doctors through enquiry [37]. As it is showed in Table 2, enquiry is implemented by country doctors in every conversation with their patients.

(3) D: Is there still anything wrong with you?

P: No.

D: How about your head?

P: I feel good with my head.

D: How about your whole body?

P: I feel good too.

D: Have you been taking medicine?

P: Yes. Two white pills and two yellow ones.

D: How many times a day do you take medicine?

$\mathrm{P}$ : Once at noon and once in the evening.

D: How about in the morning?

$\mathrm{P}$ : Yes, I also take medicine in the morning.

D: So three times a day?

P: Yes.

D: OK.

In example (3), the country doctor asks seven questions one by one to enquire the patient's health condition and medicine taken. The first question "Is there still anything wrong with you?" tells us that this patient was diagnosed by the country doctor before and in this diagnosis the doctor wants to get the newest information about the patient's health status. Replied with "no", the doctor asks two more detailed questions which are about the health condition of the patient's head and body, aiming at further confirming whether the patient is fine. Having known that the patient is surely getting better, the doctor starts to ask about the patient's medication. However, hearing that medicine is taken at noon and in the evening, the doctor asks the patient whether $\mathrm{s} /$ he takes medicine in the morning, judging from which it can be inferred that the medicine should be taken three times a day and the doctor doubts and worries whether the patient is taking medicine in the right way, so on the purpose of eliminating the doubts and worries and helping the patient better, the doctor asks the sixth question "How about in the morning?". When gets the answer "yes", the doctor further confirms it by asking the last question "So three times a day?" which is also a supplementation and conclusion of the patient's answer.

When the patient forgets to answer that $\mathrm{s} /$ he also takes medicine in the morning, the doctor does not blame on the patient but asks one more question patiently and then supplements the patient's answer clearly. Via maximizing the cost to self, the doctor observes the generosity maxim not only for showing politeness to the patient, but also for getting the precious information from the patient clearer. Therefore, with the acquirement of that the patient is really getting better and taking medicine in the right way, "OK" is uttered by the doctor at last, which also conveys that the doubts and worries are cleared out of the doctor's mind.

\subsection{Instruction in Diagnosis}

Instruction in diagnosis refers to that doctors tell their patients to do something in the process of diagnosis. The 80 instructions consist of two kinds, which are direct instruction and instruction with request. The number and distribution of each kind are portrayed in Table 3.

Table 3. Instruction in Diagnosis.

\begin{tabular}{lll}
\hline Name & Number & Proportion \\
\hline Direct Instruction & 78 & $97.5 \%$ \\
Instruction with Request & 2 & $2.5 \%$ \\
\hline
\end{tabular}

As it is demonstrated in the table above, 78 of $80(97.5 \%)$ instructions in diagnosis are direct instructions and only 2 $(2.5 \%)$ are instructions with request, which shows that in the most cases, country doctors instruct their patients directly in the process of diagnosis.

\subsubsection{Direct Instruction}

Direct instruction means to tell others to do something directly.

(4) D: Have a seat. I'll take your blood pressure. Take off your sleeve and don't talk.

(5) D: Open your mouth and let me have a look at your throat. OK, now I am listening to your lungs. Take a deep breath.

In the two examples above, doctors instruct directly their patients to do something to cooperate with the diagnosis. In this way can doctors better examine and treat their patients and thus better help them recover and cure.

\subsubsection{Instruction with Request}

Instruction with request means to tell others to do something with a request, on the purpose of getting permissions as well as showing politeness.

(6) D: I am taking your blood pressure now.

P: OK. When I got up yesterday morning, I had a lot of energy. I cut the stuffing, kneaded the dough, and made the buns.

D: You are in your 80s. That's very good!

P: Eighty-four. I used to go to the doctor and take medicine very often. You see, before,

D: Please be silent for a moment and you can continue after I take your blood pressure. Is that OK?

P: OK.

Doctors are entitled to directly instruct their patients to be quiet in the process of diagnosis, while in the example above, the doctor requests the patient not to talk during taking blood pressure. Although request is unnecessary to the instruction and irrelevant to the diagnosis, it has an effect of great importance in this context, for its significance is not topical but social psychological. It is motivated and utilized for the reason that considering the patient is 84 years old, the doctor not only wants to let the patient cooperate with the diagnosis, but more importantly, wants to show politeness and respect to the senior citizen. Therefore, "Please" is uttered before "be silent". Additionally, "for a moment" shows that patient 
only needs to be silent for a while and can continue talking soon after, and that is further confirmed by "you can continue after I take your blood pressure". Moreover, "Is that $\mathrm{OK}$ ?" as a request is expressed in the end by the doctor to get the patient's agreement and simultaneously, to show more politeness and respect. By instructing the aged patient with request, the doctor minimizes the cost to the patient and observes the tact maxim, which shows the doctor's politeness as well as respect to the patient and further helps to make the patient be more cooperative in the process of diagnosis.

(7) D: What's the matter, girl?

P: Stomachache.

D: When did that begin?

P: From this morning.

D: What have you eaten?

P: Nothing.

D: Have you drunk milk?

P: No.

D: Come here and I will touch your belly, can I?

P: Yes.

The doctor in (7) is a male. After enquiring the symptoms of the girl, the doctor needs to examine the girl's stomach by touching her belly. He instructs the girl to come to him and tells her what he is going to do. In addition, "can I?" is said by the doctor to request the girl. The request itself has nothing to do with the process of diagnosis, but in this context it is vital, for its necessity is not topical but social psychological. By means of requesting the girl to get her permission to do physical check-up, the doctor minimizes the cost to her and thus observes the tact maxim, which can not only help to make the patient more cooperative in the diagnosis, but also show the doctor's politeness and more importantly, eliminate any misunderstandings. Only with the agreement of the young girl, the adult male doctor can touch her belly and examine her health condition without misgivings.

\subsection{Data Display}

Data display means to show the data to people or group.

(8) D: Your high blood pressure is $188(\mathrm{mmHg})$, your low blood pressure is $117(\mathrm{mmHg})$, and your heart rate is 90 (times / $\mathrm{min}$ ).

(9) D: Blood glucose is $12.6(\mathrm{mmol} / \mathrm{L})$.

In the two examples above, country doctors display the data of their patients' blood pressure and heart rate and blood glucose respectively to them. Doctors make clear patients' health conditions of the different items, by means of which not only can doctors help patients know their health status better and clearer, but also doctors are more convincing to assert their patients' illnesses and give them instructions. Therefore, the function of data display is not only topical but also social psychological, for when patients better know their blood pressure, blood glucose, and so on, they will be more positive and cooperative to follow doctors' instructions to get cured, which will be better for patients in turn.

\subsection{Assertion}

The definition of assertion is that "a statement saying that you strongly believe something to be true" [13]. It is an essential part in doctor-patient interactions and the indispensable result after doctors diagnose their patients, because doctors are supposed to tell their patients about their health conditions and it is the aim for patients who come to the hospitals and clinics. As it is portrayed in Table 2, assertion shows up in every conversation of country doctors with their patients.

(10) D: Let me have a look at your temperature. $39.4^{\circ} \mathrm{C}$. You have a fever, a high fever.

(11) D: Do you cough?

P: Yes.

D: How long has it been?

P: Four or five days ago.

D: OK, let me have a check.

(Doctor uses stethoscope to listen to patient's lungs)

D: Your bronchitis is very serious.

In example (10), the doctor asserts the patient's illness after displaying the data. In example (11), the doctor asserts the patient's disease after enquiring and examining. As a conversational strategy, assertion is implemented after enquiry and data display. It is the consequence of diagnosis and leads to the next conversational strategy by country doctors, which is instruction after diagnosis.

\subsection{Instruction After Diagnosis}

Instruction after diagnosis refers to that doctors give their patients instructions after asserting their health status or diseases. It is indispensable in doctor-patient conversations for it is necessary for patients and is implemented in all of the 217 conversations. 217 instructions consist of three kinds, which are simple instruction, instruction with negation, and instruction with consultation. The number and distribution of each kind are sketched in Table 4.

Table 4. Instruction after Diagnosis.

\begin{tabular}{lll}
\hline Name & Number & Proportion \\
\hline Simple Instruction & 184 & $84.79 \%$ \\
Instruction with Negation & 32 & $14.75 \%$ \\
Instruction with Consultation & 1 & $0.46 \%$ \\
\hline
\end{tabular}

As it is delineated in the table above, 184 of 217 (84.79\%) instructions after diagnosis are simple instructions. 32 $(14.75 \%)$ are instructions with negation. Only $1(0.46 \%)$ is instruction with consultation. Each kind is depicted and interpreted in the following.

\subsubsection{Simple Instruction}

Simple instruction is to tell people what to do simply.

(12) D: From now on, take medicine on time; eat more light, less salty, and less fat; come here on time to take blood pressure and exercise more.

(13) D: When you get home, use a damp cloth to wipe them all. I'll give you an ointment. Rub it on.

(14) D: Listen, hurry to the county hospital to treat your 
abnormal heart rate. It's too fast.

In the two examples above, country doctors simply instruct their patients to do something after diagnosis for treatment. Doctors in example (12) and (13) instruct their patients to do something for treatment in detail, while the doctor in example (14) instruct the patient to immediately go to the county hospital, which is much better and more advanced but more expensive than country doctors' clinics, for better treatment. The doctor violates the tact maxim for $\mathrm{s} /$ he does not help to treat the patient but increases the cost of the patient. However, it is necessary for the doctor to do so in this case, because the doctor emphasizes the serious situation in which the patient is, so as to motivate the patient to take actions for practical treatment. Moreover, when doctors cannot solve the problem for their patients, instructing them to go to a better hospital as soon as possible is an act of responsibility and professionalism.

\subsubsection{Instruction with Negation}

Instruction with negation is to tell people what to do and what to stop doing.

(15) P: I haven't taken anti-hypertensive drugs for some days. I'm drinking anti-hypertensive tea.

D: You should not. Anti-hypertensive tea can't replace anti-hypertensive drugs. Don't stop taking the medicine. Take it on time.

(16) P: I love to eat sweet.

D: You can't eat sweet. Your blood sugar is still high. Don't eat sweet. Exercise more and eat less salty.

In the two examples above, country doctors tell their patients what they should do and what they should stop doing. In example (15), the doctor asks the patient not to drink anti-hypertensive tea any more but to take anti-hypertensive drugs without interruption, and in example (16) the doctor tells the patient to stop eating sweet but to exercise more and eat less salty. After hearing that their patients are doing something wrong, the doctors do not show any agreement to them but stop them from doing so. The doctors violate the agreement maxim, but it is necessary to do so for the importance and function is not only topical but also social psychological. The doctors stimulate the patients to stop the wrong behaviors by expressing disagreements and asking them to stop directly, which will help to make the patients be more active to correct themselves and quit the wrong behaviors and correspondingly will be better for their treatment and recovery.

\subsubsection{Instruction with Consultation}

Instruction with consultation is to tell people what they should do and guide them to discuss and decide whether to do it or not. $(\mathrm{PF}=$ patient's family, who is the patient's daughter-in-law)

(17) D: It is clear that your lumbar disc is protruding. Drip can't solve the problem. I suggest you have a minimally invasive operation.

P: As long as you can stop the pain for me.

PF: I'll call XX (the patient's son) first. It is totally fine if the patient is cured. But if the patient who is 87 years old is not cured, I can't afford the responsibility.

D: OK, you communicate first. If you all agree, I'll perform the operation then.

In the conversations above, the doctor tells the patient the way to get cured but instructs the patient's family to communicate first and then decide whether to let the aged patient have the operation or not. Doctors are responsible to tell their patients the best way of treatment and it is better for patients to follow doctors' instructions to get treated as soon as possible, but in this case, before operating on the patient, the doctor let the patient's families to discuss and make the decision. With no doubt, the effect is social psychological. The patient is 87 years old, on whom operating is risky. If the patient's daughter-in-law agrees to the patients' operation but the operation fails, she cannot afford the responsibility. Therefore, she needs to call her husband who is the patient's son and is more suitable and qualified both morally and legally to help make the decision. Considering that, the doctor does not blame the patient's family for delaying the treatment for the patient but sympathizes with her. The doctor observes the sympathy maxim and consequently agrees the patient's daughter-in-law to call her husband to help make the decision, which shows the doctor's understandings and politeness, and more importantly, can help to eliminate the patient's family's worries and further clear the path for the doctor to perform operation on the patient in turn.

\subsection{Explanation}

The definition of explanation is that "a statement, fact, or situation that tells you why something happened; a reason given for something" [13]. According to the content of the explanations, they are further divided into four types which are explanation with medical knowledge, explanation with government policy, explanation with patient's behavior, and explanation with slang. The number and distribution of the four types are depicted in Table 5.

Table 5. Explanation.

\begin{tabular}{lll}
\hline Name & Number & Proportion \\
\hline Explanation with Medical Knowledge & 47 & $71.21 \%$ \\
Explanation with Government Policy & 8 & $12.12 \%$ \\
Explanation with Patient's Behavior & 10 & $15.15 \%$ \\
Explanation with Slang & 1 & $1.52 \%$ \\
\hline
\end{tabular}

As it is shown in the table above, 47 of 60 (71.21\%) explanations are explanations with medical knowledge. 8 $(12.12 \%)$ are explanations with government policy. 10 $(15.15 \%)$ are explanations with patient's behavior. Explanation with slang is used only once (1.52\%). Each type is sketched and interpreted in the following.

\subsubsection{Explanation with Medical Knowledge}

Explanation with medical knowledge means to use medical knowledge to make people understand.

(18) P: Sometimes I sit there, my heart pounding. D: It's called paroxysmal tachycardia. It's OK when it happens occasionally, but if it happens frequently, you need to take medicine. 
The doctor in example above uses medical knowledge to explain the reason for the patient's symptom. The effect of explanation with medical knowledge is not only topical but also social psychological, for medical knowledge contributes more reliability and authority to explanations. Therefore, the explanation in example (19) is convincing with the medical knowledge about the causes of cerebrovascular disease and more professional with the medical terminology "paroxysmal tachycardia". By means of explaining with the help of medical knowledge, country doctors can make their patients be more trustful and respectful to them and correspondingly be more cooperative to the diagnosis and treatment. In other words, it benefits both country doctors and their patients simultaneously.

\subsubsection{Explanation with Government Policy}

Explanation with government policy means to use government policy to make people understand.

(19) D: Go to have physical check-ups regularly. Now the elderly over 65 years old are enjoying free physical check-ups.

(20) D: Have you been taking medicine?

P: Yes, three times a day.

D: You should. And for destitute families, it is free to take medicines. You don't need to spent one cent, so just take with no interruption.

"Health Management Services for the Elderly" in "National Basic Public Health Service Specification" [19] stipulates that township hospitals should provide free health management service once a year for the elderly who are aged 65 years old and above and live within the jurisdictions, and the service includes physical check-up, auxiliary examination, health guidance, lifestyle and health assessment. The doctor in example (19) uses this government policy to explain to the patient the reason for having physical check-ups regularly.

"Detailed Rules for the Implementation of Targeted Medical Poverty Alleviation and Chronic Disease Assistance in Jinan" [10] stipulates to help the destitute families who are suffering from 10 kinds of chronic diseases with free medicines, and the 10 diseases includes hypertension, type II diabetes, coronary heart disease, stroke, chronic obstructive pulmonary disease (chronic bronchitis, emphysema), osteoarthritis, liver disease (autoimmune hepatitis, cirrhosis, cholangitis, viral hepatitis), gastrointestinal disease (gastritis, enteritis, ulcer), prostate disease, skin disease (eczema, urticaria). The doctor in example (20) explains with the government policy to the patient the reason for taking medicines with no interruptions.

Doctors in the two examples above do not explain with medical knowledge the importance of having regular physical check-up and the necessity of taking medicine without interruption, but explain with government policy, the purpose and function of which is not only topical but more social psychological. The villagers especially the elderly and destitute families worry about spending much money in hospitals. Therefore, when they are told that the check-up and medicine are free of charge, the patients would feel like costing nothing but getting benefits. The doctors observe the tact maxim so as to eliminate their patients' worries of spending money in hospitals and stimulate the patients to follow the instructions after diagnosis more actively and cooperatively, which will be certainly better for the patients' treatment and recovery.

\subsubsection{Explanation with Patient's Behavior}

Explanation with patient's behavior means to make patients understand with the help of their own behaviors.

(21) D: Do you smoke?

P: Yes.

D: Your heart problem is closely related to your smoking. Quit it.

(22) D: Your blood pressure is too high. Have you taken anti-hypertensive drugs?

P: No. I feel sick in my head.

D: It's just because you didn't take the drugs. Take it as soon as possible. If you had taken it before, your blood pressure would not be high now.

The doctors in the two examples above use their patients' behaviors to explain the cause of their disease and symptom. The doctor in (21) attributes the patient's heart problem to smoking. This is explanation with patient's behavior but not with medical knowledge, for the doctor simply claims that the cause of the patient's heart problem is the action of smoking but does not explain the reason or illustrate the relation between smoking and heart disease from an academic or medical perspective. The doctor in (22) attributes the patient's symptom to not taking anti-hypertensive drugs, which is also the patient's behavior. Hearing the wrong behaviors of their patients, the doctors do not show any agreement but attribute the patients' illness to their wrong behaviors and instruct them to stopping do so. The doctors violate the agreement maxim, which is seemingly impolite to their patients but it is necessary in this context, for the effect of explaining with patient's behavior is not only topical but also social psychological. It helps to stimulate patients' guilty about their own wrong behaviors in the past, and motivate them to correct their mistakes as soon as they can and be more cooperative to the instructions after diagnosis from their doctors, which will be better for patients' treatment and recovery.

\subsubsection{Explanation with Slang}

Explanation with slang means to use slang to make people understand.

(23) D: How heavy are you?

P: 110 pounds or so. No flesh left.

D: How old are you?

P: 73 .

D: That's not bad. It's very rare to be thin in old age! (有钱难买老来瘦啊! )

The doctor in example above tells the patient who is 73 years old that being thin is not bad and explains it with a Chinese slang “有钱难买老来瘦”, which is also written as “千金难买老来寿” in Chinese and means that it is very rare being thin in old age [31]. The slang itself is not absolutely right from the medical perspective, but the function and effect 
of using it in the conversation above is not only topical but also social psychological. First, by means of explaining with the slang, the doctor encourages the patient not to be worried, for being thin in old age is a rare and good thing. Second, “瘦” which means thin in Chinese is the homophone of “寿” which means longevity. Therefore, the doctor heartens the patient twice with one slang, for it also indicates that the patient can live a long life. The doctor praises the patient and thus observes the approbation maxim, which not only shows the doctor's politeness to the patient, but more importantly encourages the patient to keep in a positive attitude, and in consequence it will be better for the patient.

\subsection{Comparison}

The definition of comparison is "the process of comparing two or more people or things" [13]. According to the way of comparing, the 10 comparisons are further divided into two kinds which are vertical comparisons and horizontal comparisons. The number and distribution of the two kinds of comparisons are depicted in Table 6.

Table 6. Comparison.

\begin{tabular}{lll}
\hline Name & Number & Proportion \\
\hline Vertical Comparison & 7 & $70 \%$ \\
Horizontal Comparison & 3 & $30 \%$ \\
\hline
\end{tabular}

As it is demonstrated in the table above, 7 of $10(70 \%)$ comparisons are vertical comparisons. $3(30 \%)$ are horizontal comparisons. Each kind is portrayed and interpreted in detail in the following.

\subsubsection{Vertical Comparison}

Vertical comparison refers to comparing a thing with its past, present, or future [6].

(24) D: Your blood pressure was not high before, but it's a little high this time. Come back in a few days and take your blood pressure again.

After taking the patient's blood pressure, the doctor first mentions that the blood pressure of the patient was not high before, and then asserts that it is a little high this time. Comparing the patient's health status now with its past is unnecessary in the process of diagnosis. Moreover, the doctor does not praise the patient but instead emphasizes his/her health condition is not as good as before and instructs the patient to come back again, which means the doctor violates the approbation maxim in the conversation above. However, the function and effect of using the comparison is not only topical but also social psychological. Through comparing the patient's blood pressure at present with it in the past, the doctor implies to the patient that his/her health should be taken good care of from now on because the blood pressure has risen. It stimulates the patient to reflect on his/her behaviors and living habits in the past, and motivates him/her to correct the wrong ones and follow the instruction after diagnosis from the doctor actively, which will consequently be better for patient's recovery and health statue in turn.

(25) D: Your blood pressure now is 160 and 90. It's a little high, so keep taking medicine. But it's better than last time. Your blood pressure was over 200 then.

In the example above, after displaying data, asserting, and giving instruction after diagnosis, the doctor compares the patient's blood pressure this time with last time, and praises the patient for the blood pressure is better than before. The doctor observes the approbation maxim, which not only shows politeness to the patient, but more importantly, encourages the patient to stay on treatment positively, which will consequently be better for the patient's recovery. Therefore, even though the comparison employed by the doctor is unnecessary to the diagnosis, but the function is not only topical but more social psychological.

Via implementing vertical comparison, country doctors may observe or may violate the maxim of politeness principle, and it is judged from the content of the comparison. However, the purpose of vertical comparisons is the same, which is to help patients get recovered better and keep in good health.

\subsubsection{Horizontal Comparison}

Horizontal comparison refers to the comparison between two or more things of the same kind, such as the comparison between two countries or two regions, which can help people understand their strengths and weaknesses more clearly [6]. As it is depicted in Table 6, horizontal comparison is utilized in 3 country doctor-patient dialogues, which accounts $30 \%$ of the total comparisons. According to the direction of horizontal comparison, it is further divided into two kinds which are upward comparison and downward comparison. The number and distribution of the two kinds of horizontal comparisons are portrayed in Table 7 .

Table 7. Horizontal Comparison.

\begin{tabular}{lll}
\hline Name & Number & Proportion \\
\hline Upward Comparison & 1 & $33.33 \%$ \\
Downward Comparison & 2 & $66.67 \%$ \\
\hline
\end{tabular}

As it is demonstrated in the table above, 1 of $3(33.33 \%)$ horizontal comparisons is upward comparison and $2(66.67 \%)$ are downward comparisons. Each of them is described and discussed in the following.

\section{(i) Upward Comparison}

Upward comparison is to compare with someone better than us [28]. "Upward comparison helps people to achieve and maintain superiority by serving self-evaluative and self-improvement functions" [3].

(26) D: You should stop drinking alcohol and quit smoking. P: Well, I'm already 70 years old.

D: Only 70, not very old. Compared with those in their 90 s, you are still young!

In the dialogues above, the patient's words 'I'm already 70 years old" expresses his/her attitude towards and perception of life that he/she has lived for a long time and need not restrain him/herself any more. In other words, the patient does not want to stop drinking and quit smoking, even though it will be harmful for the patient's health. The doctor does not praise the patient for his/her long life but emphasizes that he/she has 
lived not so long as those who are in their 90s via comparing the patient with people of 90 years old, which means the doctor makes upward comparison and violates the approbation maxim. Nevertheless, the comparison is irreplaceable in this context, for its importance and effect is social psychological. Upward comparison helps and inspires people to achieve superiority by serving self-improvement functions. Therefore, via comparing the patient with people who have lived longer than him/her, the doctor stimulates the patient to self-improve to achieve superiority and thus motivates the patient to take good care of his/her health to live longer. In consequence, it is helpful for the patient to stop drinking and quit smoking actively, which will be definitely better for the patient's health in turn.

\section{(ii) Downward Comparison}

Downward comparison is to compare with someone worse than us [28]. "The theory of downward comparison posits that persons experiencing negative affect can enhance their subjective well-being through comparison with a less fortunate other, the process occurring on either a passive basis or an active basis" [32].

(27) D: Don't worry about it. You have too much pressure on your mind.

P: Oh, too much suffering. I can't stand the premature beat.

D: Let's treat it little by little. Your illness is not very serious. There are some people who are more seriously ill, and they all get cured little by little.

The doctor encourages the patient who is in bad mood and under much pressure because of suffering from premature beat not to worry and tells the patient that people who were worse than him/her have already been cured. On the one hand, the doctor tries to lower the patient's psychological cost and thus observes the tact maxim and shows politeness. On the other hand, the doctor makes downward comparison between the patient and the ones who were more seriously ill, the function of which is not only topical but more social psychological. Because persons experiencing negative affect can enhance their subjective well-being through comparison with a less fortunate other, via comparing the patient with the more seriously ill people, the doctor helps to improve the patient's subjective well-being, and via telling that those more seriously ill people can get cured, the doctor indicates that the patient can also get cured. In this way, the doctor not only shows politeness but more importantly encourages the patient to stay on treatment bravely and optimistically, which will be certainly better for patient's health and recovery.

\subsection{Comforting}

Comforting someone means to "make them feel less worried, unhappy, or upset, for example by saying kind things to them" [27].

(28) D: When did you have a cerebral thrombus?

P: From last year.

D: Your blood pressure is normal now. So take medicine on time; exercise often; measure blood fat and have check-up regularly. Everything is and will be fine. Don't worry!

After asserting the blood pressure and giving instructions after diagnosis to the patient who has cerebral thrombus, the doctor adds two more sentences which are "Everything is and will be fine" and "Don't worry" to comfort the patient. These two sentences are unnecessary to the diagnosis, but the function and effect of them is not only topical but more social psychological. By comforting the patient who is suffering from cerebral thrombus, the doctor reduces his/her pressures and psychological costs, which means the doctor observes the tact maxim and shows politeness to the patient, and moreover, the doctor encourages the patient to stay on treatment positively and live optimistically, which will be certainly beneficial for the patient's recovery and health.

(29) D: I'll give you a plaster. Don't cry. I won't give you an injection. Don't worry.

The patient in the example above is a nine-year-old girl. Judging from what the doctor says, we know that the girl is crying in the process of diagnosis. The doctor comforts the girl by means of telling her that she will not get an injection and not to worry, which is unnecessary to the diagnosis, but the function and effect is more social psychological than topical. Children are afraid of injection. Therefore, through comforting the crying little girl, the doctor eliminates the tension in her mind and minimizes her psychological cost. That is to say, the doctor observes the tact maxim and shows politeness to the patient, and furthermore, the doctor helps the little girl to be relaxed in the process of diagnosis and more cooperative to the treatment, which will be favorable for sure for her recovery in consequence.

\subsection{Praise}

The definition of praise is "words that show approval of or admiration for somebody or something" [13].

(30) D: You are recovering well!

(31) D: Your high pressure is 143, low pressure 82, heart rate 75 . You are in good health during this period, so keep it!

In the two examples above, the doctors praise their patients for their good recovery and good health condition, the function of which is not only topical but also social psychological. As two-factor theory states, motivators such as recognition for one's achievement give people positive satisfaction which arises from the intrinsic conditions of their work itself, such as recognition, achievement, or personal growth [11]. Through praising their patients, the country doctors recognize their patients" achievements in their "work" which is staying on treatment, so that not only do the country doctors observe the approbation maxim and show politeness, but moreover, they motivate and encourage their patients to stay on treatment more positively or keep in good health more actively, which will be certainly better for patients' health in turn.

\subsection{Warning}

The definition of warning is "something which is said or 
written to tell people of a possible danger, problem, or other unpleasant thing that might happen" [27].

(32) D: Your blood pressure is high. You must take medicine. Your low pressure is 114, high pressure 161 . Haven't you taken any medicine?

P: Not once.

D: You have to. You've had cerebral thrombus once. If it hits you again, it will be very dangerous. You won't be able to move.

Knowing that the patient who got cerebral thrombus once before and has high blood pressure now does not take any medicine, the doctor instructs the patient to take medicine without interruption and warns the patient that he/she would be in great danger if he/she were not to take medicine from now on. The doctor does not agree with the patient's wrong behavior but asks him/her to correct it and warns him/her the possible danger if the wrong behavior is not stopped, which means the doctor violates the agreement maxim, but it is necessary to do so in this context, for the function and effect of the warning from the doctor is not only topical but also social psychological. Through telling the patient of the possible danger of not taking medicine, the doctor tries to make the patient worry about his/her own health and stimulates the patient to take medicine out of fear to avoid the possible danger. In this way, the doctor helps the patient to be more cooperative and active to the treatment, which will be better for certain for the patient's recovery and health.

\subsection{Kinship Address}

Kinship address means that people use kinship terms to address others. In many languages, kinship terms are only used to address family members and relatives, while in some languages, kinship terms are also utilized to address non-kin [30]. In Chinese, the kinship terms are often employed to address non-kin. "In Chinese not only seniors, but juniors, even strangers can also be addressed by kinship terms" [33]. "Choosing senior kinship terms to address non-relatives, both known and unknown, can show one's respect and politeness for them" [33].

(33) D: How do you do, uncle?

(34) D: Grandpa, how do you feel recently?

(35) D: Have a seat, aunt.

(36) D: Grandma, your blood pressure is 160 and 90 . Still a little high.

As the four examples above demonstrate, all of the kinship terms called by country doctors to their patients are the terms for elders. Additionally, kinship address as a conversational strategy can only be utilized together with other conversational strategies. In the four examples, kinship address is implemented respectively with greeting, enquiry, instruction in diagnosis, and data display and assertion. Without those conversational strategies, kinship address itself cannot function as a conversational strategy, for kinship address alone does not convey any communicative purpose and practical significance in country doctor-patient interactions. Still, the importance of kinship address should not be overlooked, for its function and effect is not only topical but more social psychological. Using kinship terms to address the patients who are older than them, country doctors observe the tact maxim and show politeness to their patients. Furthermore, by using kinship terms, speakers attempt to establish a temporary solidarity like that between family members, and with the establishment of this kind of family solidarity, both speakers and addressees will feel closer and more intimate [33]. Therefore, by addressing their patients with kinship terms, country doctors shorten the psychological distances with their patients and thus enhance their patients' trust in them, which is not only helpful to reduce patients' strangeness and nervousness in the clinics, but also favorable for patients to be more cooperative in the process of diagnosis and more positive to the instructions after diagnosis, which will be certainly better for patients' treatment and recovery in consequence.

Furthermore, the conversational strategies above are not implemented solely but cooperatively. Different conversational strategies are employed by country doctors for topical as well as social psychological considerations, in order to better communicate with their patients and better help them be more cooperative in the process of diagnosis and more positive and active in treatment.

\section{Conclusion}

In this study, it is found 12 conversational strategies implemented by Chinese country doctors in the conversations with their patients, which are greeting, enquiry, instruction in diagnosis, data display, assertion, instruction after diagnosis, explanation, comparison, comforting, praise, warning, and kinship address. They are delineated clearly and intuitively in Figure 1. Different conversational strategies observe or violate different maxims of politeness principle and embody distinct topical and social psychological functions and effects and is needed to be employed in distinct contexts.

In the practical sense, the conversational strategies discovered in this study provide new inspirations for health professionals to better communicate with their patients and help their patients be more cooperative in diagnosis and more positive in treatments, which will help patients get recovered and cured better. In the theoretical sense, few researches focused on Chinese country doctor-patient conversations and the conversational strategies of Chinese country doctors before. Thus, this study provides a new perspective to the study on the conversation and relationship between doctors and patients and the study on conversational strategies. In addition, social psychological pragmatics is a relatively new and developing approach to interpreting interactions. By means of interpreting the utilization and function of the 12 conversational strategies of Chinese country doctors through the lens of politeness principle which is one of the theories of social psychological pragmatics and the theoretical framework of the present research, this study enriches the corpus basis and practical applications of social psychological pragmatics. Moreover, by applying motivator of two-factor theory and social comparison theory, which are all social 
psychological theories, to the interpretation of the conversational strategies, this study promotes the theoretical connotations of social psychological pragmatics.

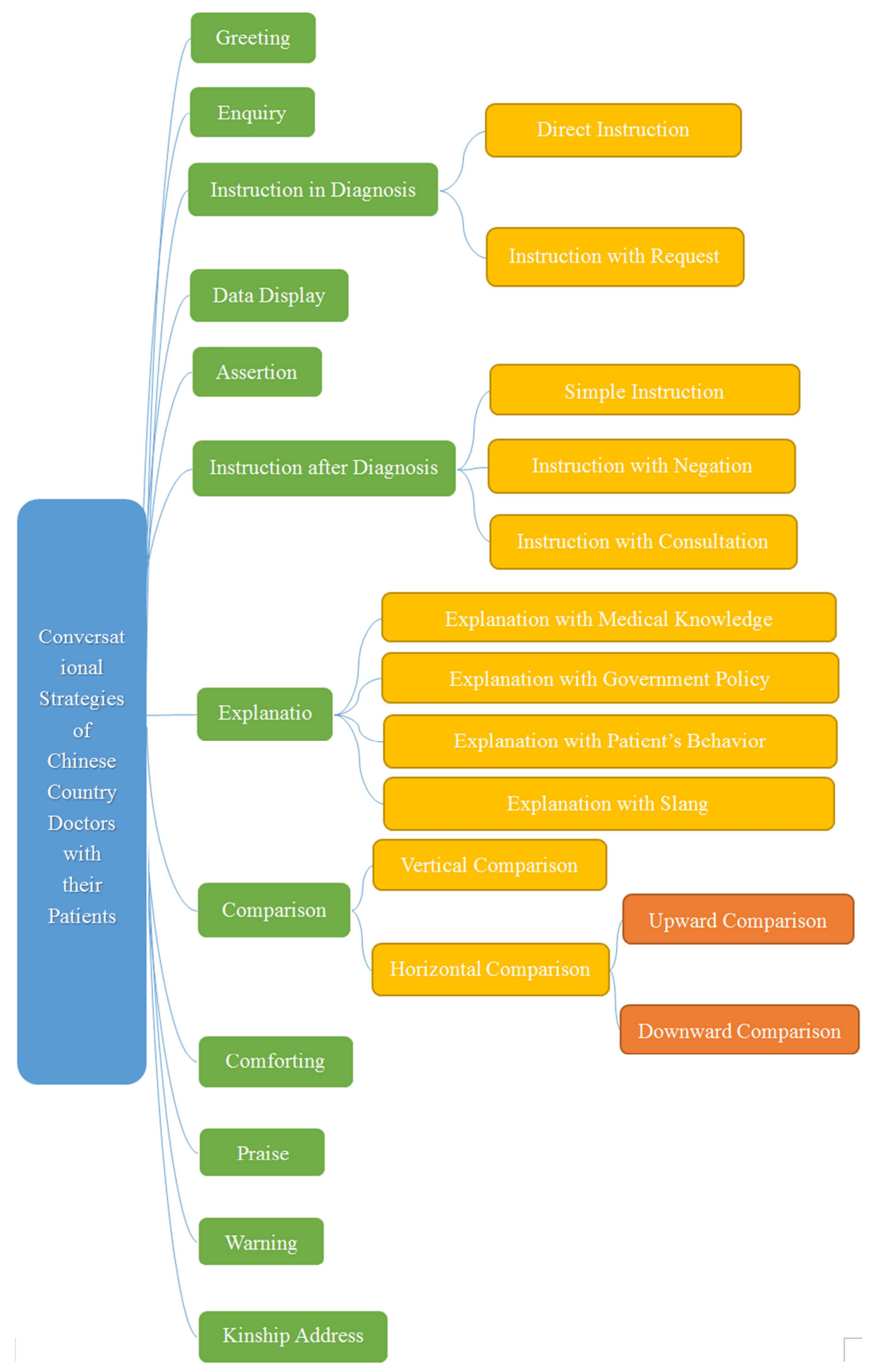

Figure 1. Conversational Strategies of Chinese Country Doctors with Patients.

There are also some limitations. For example, the conversational strategies are described and interpreted one by one, but the relations among the 12 different conversational strategies are not clearly depicted and discussed. The country doctors chosen in this study are all males and from the same province, so the conversational strategies found in this study may be not exactly the same as the strategies of female doctors or country doctors in other regions. Future researches could be conducted from multiple perspectives and we have good reasons to predict that with more profound theoretical and empirical researches, more findings can be proposed to facilitate doctor-patient communications and enhance their 
relationships and further promote the construction of a more harmonious society.

\section{References}

[1] Chen, X. (2004). A Pragmatic Study of Conversational Information Overload. Xi'an: Shaanxi Normal University Press.

[2] Chen, X. (2009). Pragmatic Studies: The Social Psychological Perspective. Foreign Languages in China, 06 (05), 46-52.

[3] Collins, R. L. (1996). For better or worse: The impact of upward social comparison on self-evaluations. Psychological Bulletin, 119 (1), 51-69.

[4] Cordella, M. (2004). Dynamic consultation: A discourse analytical study of doctor-patient communication. Philadelphia John Benjamins Publishing Company.

[5] Cruz-Sandoval, D., \& Favela, J. (2019). Incorporating conversational strategies in a social robot to interact with people with dementia. Dementia and Geriatric Cognitive Disorders, 47 (3), 140-148.

[6] Deng, W. (2009). Dictionary of Sociology. Shanghai: Shanghai Lexicographical Publishing House.

[7] Dijk, T. A. (1983). Cognitive and conversational strategies in the expression of ethnic prejudice. Text-Interdisciplinary Journal for the Study of Discourse, 3 (4), 375-404.

[8] Dörnyei, Z., \& Thurrell, S. (1994). Teaching conversational skills intensively: Course and rationale. ELT Journal, 48 (1), 40-49.

[9] Gordon, T., \& Edwards, W. S. (1997). Making the patient your partner: Communication skills for doctors and other caregivers. US: Praeger Publishers.

[10] Health and Family Planning Commission of Jinan. (2018). Detailed Rules for the Implementation of Targeted Medical Poverty Alleviation and Chronic Disease Assistance in Jinan. Retrieved from http://jnmhc.jinan.gov.cn/art/2018/7/26/art_14408_2766209.ht $\mathrm{ml}$.

[11] Herzberg, F., Mausner, B., \& Snyderman, B. B. (1959). The motivation to work (2nd ed.). New York: John Wiley.

[12] Holtgraves, T. (2002). Language as social action: Social psychology and language use. Mahwah: Psychology Press.

[13] Hornby, A. S. (2010). Oxford advanced learner's dictionary (8th ed.). Oxford: Oxford University Press.

[14] Kehe, D., \& Kehe, P. (2004). Conversation strategies: Pair and group activities for developing communicative competence. Brattleboro, VT: Pro Lingua Associates.

[15] Leaper, C. (2019). Young adults' conversational strategies during negotiation and self-disclosure in same-gender and mixed-gender friendships. Sex Roles, 1-15.

[16] Leech, G. (1983). Principles of Pragmatics. London: Longman.

[17] Lin, Y. (2016). A study on the language strategies of breaking silence in Sino-German Conversations. Unpublished master thesis, Beijing Foreign Studies University, Beijing, China.
[18] Muntigl, P., \& Turnbull, W. (1998). Conversational structure and facework in arguing. Journal of Pragmatics, 29 (3), $225-256$.

[19] National Health and Family Planning Commission of China. (2017). National Basic Public Health Service Specification $\left(3^{\text {rd }}\right.$ ed.). $\quad$ Retrieved from http://www.nhc.gov.cn/xxgk/pages/viewdocument.jsp?dispatc hDate=\&staticUrl=/jws/s3578/201703/d20c37e23e1f4c7db7b 8e25f34473e1b.shtml\&wenhao.

[20] Nguyet, N. T. M., \& Mai, L. T. T. (2012). Teaching conversational strategies through video clips. Language Education in Asia, 3 (1), 32-49.

[21] Ohtaki, S., Ohtaki, T., \& Fetters, M. D. (2003). Doctor-patient communication: A comparison of the USA and Japan. Family Practice, 20 (3), 276-282.

[22] Paling, J. (2003). Strategies to help patients understand risks. Bmj, 327 (7417), 745-748.

[23] Pallawa, B. A. (2014). Conversation strategies used by students of the English department of Tadulako University. Jurnal Pendidikan Humaniora, 1 (2), 159-168.

[24] Quirk, A., Chaplin, R., Lelliott, P., \& Seale, C. (2012). How pressure is applied in shared decisions about antipsychotic medication: A conversation analytic study of psychiatric outpatient consultations. Sociology of Health \& Illness, 34 (1), 95-113.

[25] Riggenbach, H. (1998). Evaluating learner interactional skills: Conversation at the micro level. In Young, R., \& He, A. W. (Eds.) Talking and testing: Discourse approaches to the assessment of oral proficiency, 53-67. Amsterdam: John Benjamins Publishing.

[26] Scrimin, S., Axia, G., Tremolada, M., Pillon, M., Capello, F., \& Zanesco, L. (2005). Conversational strategies with parents of newly diagnosed leukaemic children: an analysis of 4880 conversational turns. Supportive Care in Cancer, 13 (5), 287-294.

[27] Sinclair, J. (1995). Collins COBUILD English dictionary. London: Harper Collins.

[28] Suls, J., \& Wheeler, L. (2000). Handbook of social comparison: Theory and research. New York: Springer Science \& Business Media.

[29] Turnbull, W., \& Saxton, K. L. (1997). Modal expressions as facework in refusals to comply with requests: I think I should say 'no' right now. Journal of Pragmatics, 27 (2), 145-181.

[30] Wardhaugh, R. (1986). An introduction to sociolinguistics. Oxford: Basil Blackwell.

[31] Wen, D. (2011). Dictionary of Chinese Proverbs (new ed.) (Cihai ed.). Shanghai: Shanghai Lexicographical Publishing House.

[32] Wills, T. A. (1981). Downward comparison principles in social psychology. Psychological Bulletin, 90 (2), 245-271

[33] Wu, Y. (1990). The usages of kinship address forms amongst non-kin in mandarin Chinese: The extension of family solidarity. Australian Journal of Linguistics, 10 (1), 61-88.

[34] Yang, S. (2010). A Corpus-based Study of Repair in Chinese Doctor-patient Conversations. Doctoral dissertation, Shanghai International Studies University, Shanghai, China. 
[35] Yao, X. (2019). A Study of Formulation in Psychiatrist-Patient Talk-in-Interaction. Doctoral dissertation, Shandong University, Jinan, China.

[36] Yoon, S., Chan, M., Hung, W. K., Ying, M., Or, A., \& Lam, W. W. (2015). Communicative characteristics of interactions between surgeons and Chinese women with breast cancer in oncology consultation: A conversation analysis. Health Expectations, 18 (6), 2825-2840.

[37] Zhou, Y., \& Fan, Y. (2019). Discussion on inquiry characteristics of ZHANG Bing-hou. China Journal of Traditional Chinese Medicine and Pharmacy, 34 (2), 629-631. 